\title{
Changes in attitudes towards hastened death among Finnish physicians over the past sixteen years
}

Reetta P. Piili ${ }^{1,2^{*}}$ (D), Riina Metsänoja ${ }^{3}$, Heikki Hinkka ${ }^{4}$, Pirkko-Liisa I. Kellokumpu-Lehtinen ${ }^{1,2}$ and Juho T. Lehto ${ }^{1,2}$

\begin{abstract}
Background: The ethics of hastened death are complex. Studies on physicians' opinions about assisted dying (euthanasia or assisted suicide) exist, but changes in physicians' attitudes towards hastened death in clinical decision-making and the background factors explaining this remain unclear.

The aim of this study was to explore the changes in these attitudes among Finnish physicians.

Methods: A questionnaire including hypothetical patient scenarios was sent to 1182 and 1258 Finnish physicians in 1999 and 2015, respectively. Two scenarios of patients with advanced cancer were presented: one requesting an increase in his morphine dose to a potentially lethal level and another suffering a cardiac arrest. Physicians' attitudes towards assisted death, life values and other background factors were queried as well. The response rate was $56 \%$.

Results: The morphine dose was increased by 25\% and 34\% of the physicians in 1999 and 2015, respectively $(p<0$. 001). Oncologists approved the increase most infrequently without a significant change between the study years (15\% vs. $17 \%, p=0.689$ ). Oncological specialty, faith in God, female gender and younger age were independent factors associated with the reluctance to increase the morphine dose. Euthanasia, but not assisted suicide, was considered less reprehensible in 2015 ( $p=0.008)$. In both years, most physicians (84\%) withheld cardiopulmonary resuscitation.

Conclusion: Finnish physicians accepted the risk of hastening death more often in 2015 than in 1999. The physicians' specialty and many other background factors influenced this acceptance. They also regarded euthanasia as less reprehensible now than they did 16 years ago.
\end{abstract}

Keywords: Clinical ethics, Decision-making, End-of-life care, Euthanasia

\section{Background}

Discussions about the ethical justification of hastened death due to unbearable suffering are ongoing. Assisted death through euthanasia or physician-assisted suicide (PAS) has been legalized in seven countries (five states in the United States of America) thus far [1]. In addition, public support for euthanasia and PAS is mounting all over Western Europe, while some decline has been observed in the United States of America and Eastern Europe $[1,2]$. Today, there are debates about the legalization of euthanasia in many countries, including Finland, where the

\footnotetext{
* Correspondence: piili.reetta.p@student.uta.fi

${ }^{1}$ Faculty of Medicine and Life Sciences, University of Tampere, Tampere, Finland

${ }^{2}$ Department of Oncology, Palliative Care Unit, Tampere University Hospital, Teiskontie 35, R-building, 33520 Tampere, Finland

Full list of author information is available at the end of the article
}

government is currently considering options after a civil motion demanding the legalization of euthanasia. At the same time, the importance of palliative care and patient-centred decision- making has been increasingly recognized among health care professionals and the general public in European countries including Finland [3-9].

Palliative care, by definition, intends to neither hasten nor postpone death [10]. The International Association for Hospice and Palliative Care and the European Association for Palliative Care have recently stated that euthanasia and PAS should not be included as part of the clinical practice of palliative care [11, 12]. Attitudes among physicians towards assisted death are not widely studied, but several surveys do demonstrate a lower amount of support from physicians for euthanasia and PAS when compared to support from the general public [1].

(C) The Author(s). 2018 Open Access This article is distributed under the terms of the Creative Commons Attribution 4.0 International License (http://creativecommons.org/licenses/by/4.0/), which permits unrestricted use, distribution, and reproduction in any medium, provided you give appropriate credit to the original author(s) and the source, provide a link to the Creative Commons license, and indicate if changes were made. The Creative Commons Public Domain Dedication waiver (http://creativecommons.org/publicdomain/zero/1.0/) applies to the data made available in this article, unless otherwise stated. 
Questions about hastening death in end-of-life care are complex and may include ethical concerns broader than just euthanasia or PAS. Although clear definitions have been specified for euthanasia and PAS [12], which lead to a clearly assisted death, the term "hastened death" is unspecified and has many interpretations. The termination of life-sustaining treatments may be confused with euthanasia and PAS among the public and physicians [13]. The term "double effect" has been used when the act intended to do good (e.g., relief of suffering) justifies the foreseeable danger of harm (e.g., hastened death) [14]. The use and dosing of opioids during end-of-life care is a commonly used example when talking about the double effect: does the intent to treat pain or breathlessness outweigh the risk of potentially hastening death $[15,16]$ ?

However, there is growing evidence that even though high doses of opioids may cause respiratory depression [17-19], they do not seem to hasten death during end-of-life care [20, 21]. In a large multinational study by Miccinesi et al., there was general approval for alleviating symptoms with a possibly life-shortening treatment [22]. In another study from the United Kingdom (UK), physicians reported that they had at least some intention to hasten death in $7.4 \%$ of the deaths evaluated [23]. Physicians' attitudes towards hastened death through a dual effect and the background factors influencing these decisions remain largely unknown.

The aims of our study were to elucidate how, if at all, the attitudes and values towards assisted death among Finnish physicians have changed over the past 16 years and to determine the attitudes and background factors affecting physicians' willingness to accept hastened death in a hypothetical patient scenario.

\section{Methods}

\section{Participants}

A postal survey was conducted in spring 1999 and in autumn 2015. In both years, the questionnaire was sent to 500 general practitioners (GPs), 300 surgeons, and 300 internists randomly selected from the register of the Finnish Medical Association and to all Finnish oncologists ( $n=82$ in 1999 and $n=158$ in 2015). Reminders were sent twice to non-respondents. A cover letter including an introduction to the study and an assurance of anonymity was mailed together with the questionnaire. It was also stated in the cover letter, that answering to the questionnaire was completely voluntary. This study was approved by the Regional Ethics Committee of Tampere University Hospital, Finland (R15101).

\section{Questionnaire}

The questionnaire included seven hypothetical patient scenarios. Following the patient scenarios, attitudes regarding several moral and ethical aspects were assessed with a 100-mm visual analogue scale (VAS) from "definitely agree" $(0 \mathrm{~mm})$ to "definitely disagree" $(100 \mathrm{~mm})$. These included, for example, statements concerning euthanasia, palliative care, the role of religion in ethical decisions, advanced care directives and health care economics together with physicians' satisfaction with their own health, work and salary (Tables 2 and 3). Physicians' personal conceptions of professional status and their own health, family life, religion, and nature and standard of living were assessed using a four-point Likert scale (Table 2). The questionnaire has been previously used and validated with Finnish physicians [24-26].

\section{Patient scenarios}

In this study, we included two patient scenarios:

In scenario 1, a 60-year-old male patient is suffering from prostatic cancer with metastases. Metastases in the thoracic spine led to total paraparesis 1 month earlier. There is no hope for a cure. The patient is well aware of the situation. He has totally lost his will to live. When you are together with him alone, he asks for a sufficient dose of morphine to "get away". You have denied the overdose, explaining that it is against your ethical principles. During the following days, you notice that the patient asks you to double his morphine dose because of unbearable pain. The anti-inflammatory pain medication is at its maximum dose and you suspect if the pain is real (this sentence was removed from the scenario in 2015 as it did not comply with current treatment guidelines for cancer pain). You suppose that increasing the dose in such a way would lead to the patient's death. Your decision is which of the following: a) to raise the dose because the patient has the right to sufficient pain relief in this end-of-life (terminal) care situation; b) to try to help the patient in other ways, such as with antidepressants, thus continuing with morphine dosing according to given guidelines; c) I can't say; or d) give another solution:

In scenario 2, a 32-year-old female patient is brought by ambulance to the emergency unit. She is accompanied by her husband who says his wife has inoperable brain cancer. She has been receiving maximum radiotherapy, but this was discontinued 3 weeks ago. She has deteriorated considerably during the past week. The patient has now had an epileptic seizure and has been unconscious since the attack. After $20 \mathrm{~min}$ at the hospital the patient stops breathing, and there is no pulse. Your treatment decision is which of the following: a) to start cardiopulmonary resuscitation (CPR) or b) to withhold CPR. 


\section{Statistical analysis}

The answers concerning the doubling of the morphine dose in scenario 1 were converted to two options: "I accept" (response a) and "I do not accept" (other solutions). The answers on the 4- point Likert scale concerning values were converted to the following 2-point scale: 1-2 for "not important" and 3-4 for "important".

Two-scale background factors and values were tested using the Pearson chi-square test.

Continuous variables were tested using an independent-variables $t$-test or the Mann-Whitney U- test if the data were not normally distributed. Two-sided $p$-values less than 0.05 were considered as statistically significant.

\section{Logistic regression analysis}

A forward stepwise logistic regression was used to create a model explaining the decision to increase the morphine dose. Background factors, life values, and attitudes, shown in Table 2, were all included in the model. The $p$-value limit for significance was set at 0.10 to enter and 0.15 to remove from the model.

Data analyses were performed using IBM SPSS Statistics for Windows, Version 23.0 (Armonk, NY: IBM Corp. Released 2014).

\section{Results}

In total, 1373 valid responses were received (response rate 56\%). Characteristics of the physicians according to the year of response are shown in Table 1. Compared to respondents in 1999, respondents in 2015 were older $(p<0.001)$, had longer working experience $(p<0.001)$ and were more often women $(p<0.001)$.

\section{Change in attitudes}

The attitudes, personal factors and life values of the responding physicians in 1999 and 2015 are shown in Table 2.

Euthanasia and withdrawal of life-sustaining treatments were considered slightly less reprehensible in 2015 than in 1999, whereas attitudes towards assisted suicide did not change significantly. In 2015, physicians more often believed that good palliative care enables a good death and found end-of-life care satisfying, although they were less often actually involved in end-of-life care than the respondents in 1999. Advance directives were considered more helpful in 2015, although physicians still rarely had their own advance directives. The impact of physicians' background factors, faith in God, and religion on ethical decisions decreased between 1999 and 2015. The length of life, family, and cleanliness of environment were thought to be more important in 2015 , while success in their professional career was less important.

\section{Change in decision-making}

In the case in scenario 1, physicians were significantly more willing to increase the morphine dose in 2015 $(n=219,34 \%)$ than in $1999(n=180,25 \%)(p<0.001)$. This willingness increased in all groups of physicians, except among oncologists, who were also the most unwilling to do this in both years (Fig. 1). In contrast, $84 \%$ of the physicians decided to withhold CPR in case scenario 2 in both years. There were no significant changes regarding this decision about CPR among the different physician groups between the study years.

\section{Factors associated with physicians' willingness to increase the morphine dose}

Difference in the attitudes of physicians who accepted and those who did not accept the doubling of the morphine dose in both years studied are shown in Table 3.

In 1999, leniency towards euthanasia and assisted suicide was significantly greater in those who accepted the dose increase, while this was true only for assisted suicide in 2015.

Religion had a significantly larger influence on decision-making in physicians who accepted the morphine dose increase in 1999 but not in 2015.

Factors and attitudes that independently influenced physicians' willingness to increase the morphine dose from the logistic regression analysis are shown in Table 4.

Not being an oncologist was the most striking factor associated with physicians' willingness to increase the morphine dose. In addition, physicians who were male, were older, did not believe in God, accepted assisted suicide, had doubts about physicians' ability to assess cancer pain, and responded in 2015 were also more likely to be willing to increase the morphine dose. However, physicians' decisions about CPR for the patient in scenario 2 and their attitudes towards euthanasia or withdrawal of life-sustaining treatments did not influence their decision to accept the escalation of the morphine dose.

\section{Discussion}

Our study shows that some Finnish physicians' attitudes and life values have changed substantially during the last 16 years. Their approval of euthanasia has slightly increased, whereas their acceptance of physician-assisted suicide (PAS) has remained low. In an end-of-life patient case scenario, physicians show an increasing willingness to give a high morphine dose, which might potentially hasten death. In logistic regression analysis, not being an oncologist, being male, and not believing in God were the most important background factors associated with physicians' willingness to increase the morphine dose.

In our study Finnish physicians were less opposed to euthanasia now than they were 16 years ago. This finding is in agreement with previous studies showing 
Piili et al. BMC Medical Ethics (2018) 19:40

Page 4 of 10

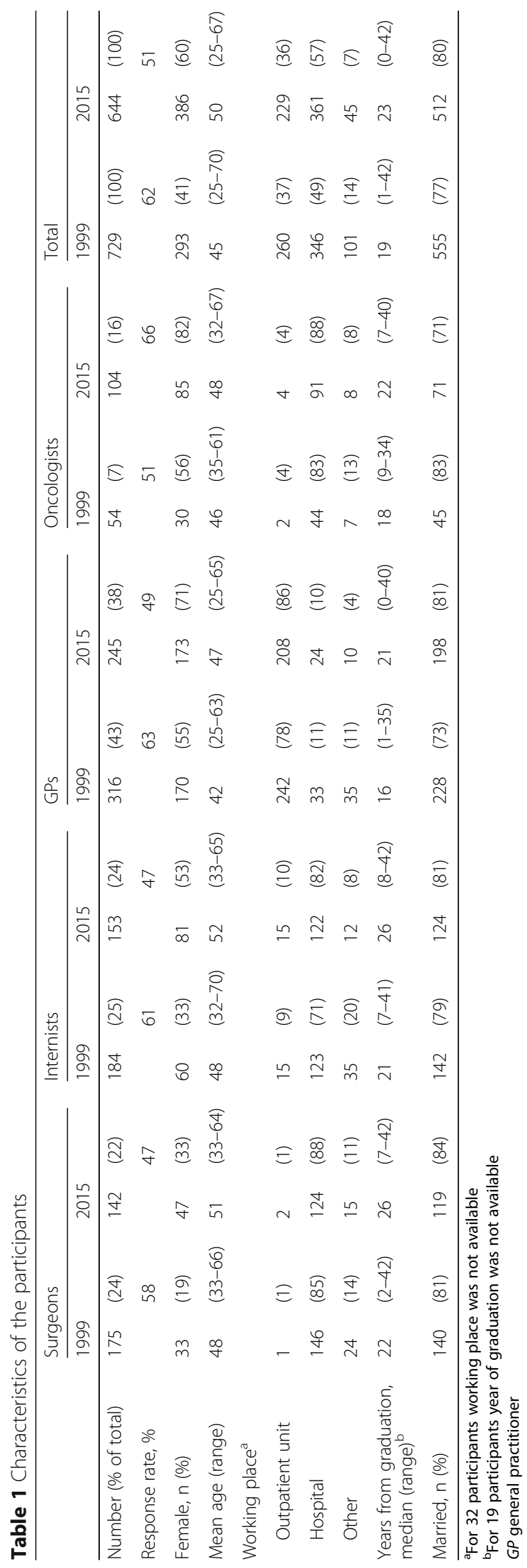


Table 2 Attitudes, background factors and life values of the physicians in 1999 and 2015

\begin{tabular}{|c|c|c|c|c|c|}
\hline \multirow{2}{*}{ Attitudes, median VAS (IQR) } & \multicolumn{2}{|l|}{1999} & \multicolumn{2}{|c|}{2015} & \multirow[t]{2}{*}{$P$-values* } \\
\hline & & & & & \\
\hline Active euthanasia is reprehensible & 17 & $(6-51)$ & 25 & $(5-66)$ & 0.008 \\
\hline Withdrawal of life-sustaining treatments is reprehensible & 89 & $(76-95)$ & 93 & $(76-99)$ & $<0.001$ \\
\hline Assisted suicide is reprehensible & 14 & $(5-38)$ & 13 & $(2-52)$ & 0.480 \\
\hline End-of-life care is satisfying & 36 & $(19-52)$ & 15 & $(3-35)$ & $<0.001$ \\
\hline People should pay costs of factitious diseases by themselves & 44 & $(27-72)$ & 78 & $(46-93)$ & $<0.001$ \\
\hline Advance directives have been helpful in my decisions & 35 & $(14-54)$ & 10 & $(2-29)$ & $<0.001$ \\
\hline Good palliative care enables good death & 17 & $(9-28)$ & 4 & $(1-12)$ & $<0.001$ \\
\hline Physicians can't estimate cancer pain & 40 & $(25-70)$ & 47 & $(27-72)$ & 0.042 \\
\hline Religion has influence when I make ethical decisions & 65 & $(31-93)$ & 81 & $(47-98)$ & $<0.001$ \\
\hline Being a doctor gives me satisfaction & 20 & $(11-30)$ & 7 & $(2-18)$ & $<0.001$ \\
\hline My health is excellent & 20 & $(10-32)$ & 14 & $(6-26)$ & $<0.001$ \\
\hline I feel burn out, tired to work & 84 & $(63-94)$ & 89 & $(71-97)$ & $<0.001$ \\
\hline I'm pleased with my salary & 72 & $(37-87)$ & 22 & $(7-50)$ & $<0.001$ \\
\hline It is waste of resources to treat patients $>80$ years in ICU & 73 & $(49-86)$ & 77 & $(54-93)$ & $<0.001$ \\
\hline \multicolumn{6}{|l|}{ Background factors and life values, n (\%) } \\
\hline Having children & 600 & (85) & 555 & (88) & 0.057 \\
\hline Having own advance directive & 38 & (5) & 38 & (6) & 0.668 \\
\hline Taking care of end-of-life patients in practice (last 2 years) & 529 & (75) & 418 & (65) & $<0.001$ \\
\hline Taking care of a family member in end-of-life & 513 & (73) & 314 & (49) & $<0.001$ \\
\hline Being afraid of death (Fear-of-death index) & 580 & (80) & 544 & (86) & 0.006 \\
\hline Length of life is important & 412 & (59) & 524 & (87) & $<0.001$ \\
\hline Health is important & 711 & (99) & 610 & (99) & 0.027 \\
\hline Family is important & 686 & (95) & 607 & (99) & $<0.001$ \\
\hline Clean environment is important & 666 & (93) & 599 & (98) & $<0.001$ \\
\hline High standard of living is important & 358 & (50) & 398 & (65) & $<0.001$ \\
\hline Faith in God is important & 338 & (48) & 253 & $(42)$ & 0.024 \\
\hline Success in professional career is important & 639 & (89) & 377 & (62) & $<0.001$ \\
\hline
\end{tabular}

VAS visual analogue scale

IQR interquartile range

ICU intensive care unit

*Mann-Whitney u-test for attitudes and Pearson Chi-Square for background factors and life values

Attitudes are expressed on a visual analogue scale (VAS) from $0 \mathrm{~mm}$ (definitely agree) to $100 \mathrm{~mm}$ (definitely disagree)

increased acceptance of euthanasia in Europe as well as in Finland [1, 2]. However, attitudes towards euthanasia were measured with a continuous visual analogue scale (VAS) on a scale from $0 \mathrm{~mm}$ (reprehensible) to $100 \mathrm{~mm}$ (not reprehensible) in our study rather than with a dichotomous question (i.e., if the physician accepts or does not accept euthanasia).

Although using a VAS scale might have caused some confusion, doctors are generally familiar with its use. This type of assessment might provide more appropriate insight into this complex ethical question. Of note, the VAS median value in 2015 was still only $25 \mathrm{~mm}$ and the absolute difference compared to the value in 1999 was
$8 \mathrm{~mm}$. Thus, our results highlight the controversial attitude towards euthanasia, which might not be found in earlier studies; for example, a previous study showed that $46 \%$ of Finnish physicians supported legalization of euthanasia [2].

In contrast to other studies [1], Finnish physicians considered PAS even more reprehensible than euthanasia and this has not changed at all during the past 16 years. Determining whether this somewhat conflicting result is due to a true difference in the attitudes towards these two procedures or just less knowledge about the process of PAS in Finland could be an aim of future research. 


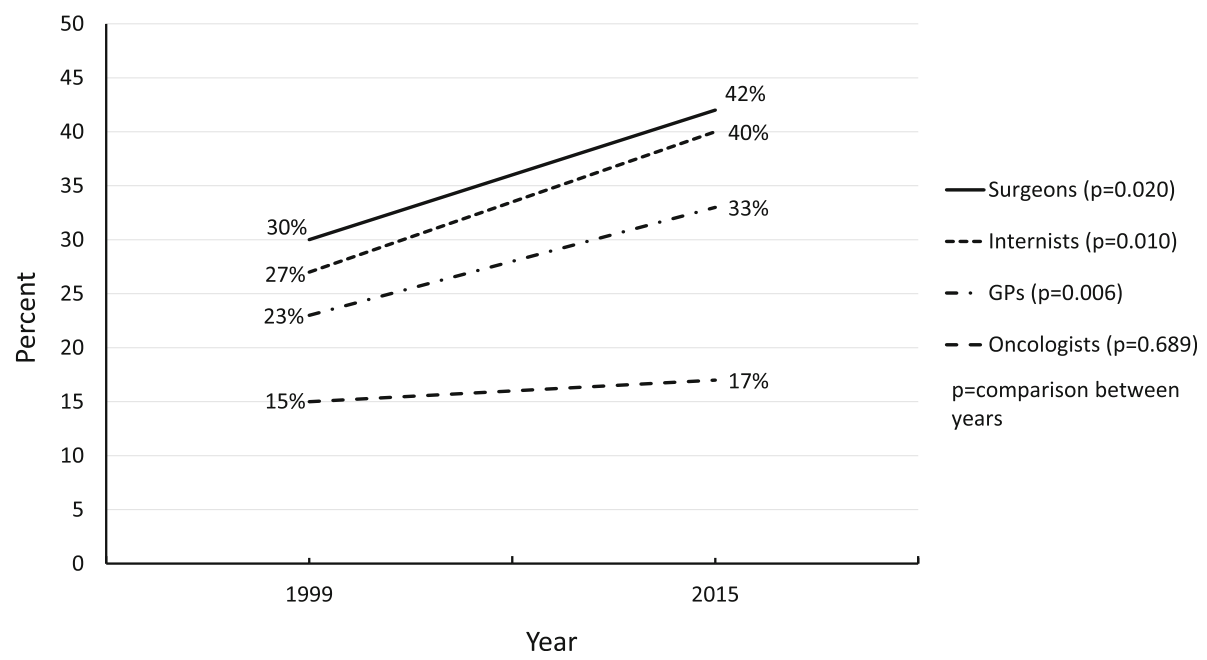

Fig. 1 Proportion of respondents who were willing to increase the morphine dose among different physician groups in 1999 and 2015

We asked if euthanasia or assisted suicide were reprehensible or not with a VAS scale to evaluate the personal ethical attitudes of the physicians rather than their opinions on the general justification of these issues. Therefore, our results represent somewhat different aspect of these issues compared to the findings of studies that inquired about physicians' opinions on the legalization of euthanasia or PAS. This might partly explain the differences in the results of the present and previous studies $[1,2]$.
According to this study, Finnish physicians do not consider withdrawal of life-supporting treatments reprehensible. Although there was a statistically significant change between the study years, the absolute difference was only $4 \mathrm{~mm}$. Our results are in line with the results from a large, international study by Löfmark et al. where $72-86 \%$ of the physicians surveyed reported experiencing foregoing life-supporting treatment and only 1-6\% reported never being willing to do so [27].

Table 3 Attitudes of physicians who were willing or unwilling to increase the morphine dose in 1999 and 2015

\begin{tabular}{|c|c|c|c|c|c|c|c|c|c|c|}
\hline \multirow{3}{*}{$\frac{\text { Attitudes, median VAS (IQR) }}{\text { Active euthanasia is reprehensible }}$} & \multicolumn{5}{|c|}{$\begin{array}{l}1999 \\
\text { Increasing the morphine dose }\end{array}$} & \multicolumn{5}{|c|}{$\begin{array}{l}2015 \\
\text { Increasing the morphine dose }\end{array}$} \\
\hline & \multicolumn{2}{|c|}{ Yes } & \multicolumn{2}{|l|}{ No } & \multirow{2}{*}{$\frac{P \text {-value }}{<0.001}$} & \multicolumn{2}{|l|}{ Yes } & \multicolumn{2}{|l|}{ No } & \multirow{2}{*}{$\frac{P \text {-value }}{0.162}$} \\
\hline & 37 & $(11-69)$ & 14 & $(5-39)$ & & 33 & $(5-72)$ & 24 & $(4-64)$ & \\
\hline Withdrawal of life-sustaining treatments is reprehensible & 92 & $(83-96)$ & 88 & $(72-95)$ & 0.003 & 95 & $(80-99)$ & 93 & $(75-98)$ & 0.133 \\
\hline Assisted suicide is reprehensible & 27 & $(9-61)$ & 11 & $(4-28)$ & $<0.001$ & 28 & $(2-68)$ & 10 & $(1-49)$ & $<0.001$ \\
\hline End-of-life care is satisfying & 38 & $(19-51)$ & 34 & $(18-52)$ & 0.683 & 16 & $(2-30)$ & 14 & $(3-45)$ & 0.363 \\
\hline People should pay costs of factitious diseases by themselves & 40 & $(23-65)$ & 47 & $(29-75)$ & 0.047 & 78 & $(49-94)$ & 77 & $(47-93)$ & 0.341 \\
\hline Advance directives have been helpful in my decisions & 31 & $(10-55)$ & 36 & $(15-54)$ & 0.199 & 12 & $(2-29)$ & 10 & $(2-28)$ & 0.723 \\
\hline Good palliative care enables good death & 19 & $(10-25)$ & 16 & $(9-29)$ & 0.833 & 4 & $(1-13)$ & 4 & $(1-13)$ & 0.869 \\
\hline Physicians can't estimate cancer pain & 35 & $(22-70)$ & 41 & $(27-71)$ & 0.056 & 44 & $(23-69)$ & 50 & $(29-74)$ & 0.006 \\
\hline Religion has influence when I make ethical decisions & 77 & $(44-94)$ & 57 & $(30-92)$ & 0.040 & 86 & $(49-98)$ & 78 & $(45-98)$ & 0.130 \\
\hline Being a doctor gives me satisfaction & 21 & $(11-29)$ & 19 & $(11-30)$ & 0.456 & 7 & $(1-19)$ & 7 & $(2-18)$ & 0.928 \\
\hline My health is excellent & 21 & $(10-35)$ & 20 & $(10-31)$ & 0.273 & 15 & $(5-27)$ & 14 & $(06-25)$ & 0.751 \\
\hline I feel burn out, tired to work & 84 & $(68-93)$ & 84 & $(62-94)$ & 0.701 & 88 & $(75-96)$ & 89 & $(70-97)$ & 0.843 \\
\hline I'm pleased with my salary & 77 & $(51-90)$ & 70 & $(35-87)$ & 0.082 & 22 & $(8-50)$ & 22 & $(7-51)$ & 0.759 \\
\hline $\begin{array}{l}\text { It is waste of resources to treat patients over } 80 \text { years of } \\
\text { age in ICU }\end{array}$ & 70 & $(48-86)$ & 73 & $(49-87)$ & 0.262 & 82 & $(54-94)$ & 75 & $(54-91)$ & 0.107 \\
\hline
\end{tabular}

VAS visual analogue scale

$I Q R$ interquartile range

ICU intensive care unit

*Mann-Whitney U-test

Attitudes expressed on a visual analogue scale (VAS) from $0 \mathrm{~mm}$ (definitely agree) to $100 \mathrm{~mm}$ (definitely disagree) 
Table 4 Different background factors, life values and attitudes explaining physicians' decision to increase the morphine dose $(n=323)$ versus not $(n=767)$ in forward logistic regression analysis

\begin{tabular}{|c|c|c|c|c|}
\hline & $n$ & $O R$ & $(95 \%$ Cl) & $P$-value \\
\hline \multicolumn{5}{|l|}{ Year of the survey } \\
\hline 1999 & 578 & ref. & & \\
\hline 2015 & 512 & 1.40 & $(1.05,1.88)$ & 0.024 \\
\hline \multicolumn{5}{|l|}{ Sex } \\
\hline Female & 534 & ref. & & \\
\hline Male & 556 & 1.51 & $(1.11,2.05)$ & 0.009 \\
\hline Age & 1090 & 1.02 & $(1.01,1.04)$ & 0.007 \\
\hline \multicolumn{5}{|l|}{ Own advance directive } \\
\hline No & 1026 & ref. & & \\
\hline Yes & 64 & 1.74 & $(1.00,3.03)$ & 0.051 \\
\hline \multicolumn{5}{|l|}{ Faith in God } \\
\hline Important & 489 & ref. & & \\
\hline Not important & 601 & 1.64 & $(1.23,2.19)$ & 0.001 \\
\hline Assisted suicide is reprehensible (VAS) & 1090 & 1.13 & $(1.08,1.19)$ & $<0.001$ \\
\hline Physicians can't estimate cancer pain (VAS) & 1090 & 0.94 & $(0.89,0.99)$ & 0.021 \\
\hline Physician groups & & & & 0.014 \\
\hline Oncologists & 120 & ref. & & \\
\hline Surgeons & 252 & 2.50 & $(1.40,4.46)$ & 0.002 \\
\hline Internists & 268 & 2.37 & $(1.34,4.20)$ & 0.003 \\
\hline GPS & 450 & 2.30 & $(1.33,3.97)$ & 0.003 \\
\hline
\end{tabular}

ref, reference

$V A S$, visual analogue scale

$G P$, general practitioner

Knowledge about the benefits of palliative care has grown in recent decades, and it is considered a part of everyday care in life-threatening illnesses [10, 28, 29]. Therefore, it is not surprising that almost all of the respondents in 2015 considered palliative care as a way of enabling a good death. However, in another study only $51-70 \%$ of physicians believed that palliative care was able to prevent the need for euthanasia and PAS [22].

Although advanced care planning has shown a positive impact on the quality of end-of-life care [30, 31], the prevalence of advance directives varies largely. In the United States, the prevalence of advance directives seems to have increased from approximately $10 \%$ up to $21-55 \%$ among the elderly in the last 10 years [32,33], while a Finnish study from 2004 showed that only $12 \%$ of the home-dwelling elderly had a living will [34]. In our study, physicians found the advance directives of the patients now more helpful than they were in 1999, but having an advance directive of their own was still uncommon among doctors in 2015 even though they were older and more experienced than in 1999. This finding might reflect a division between personal life values and experiences in clinical work.
In general, physicians accepted potentially lethal morphine dosing more frequently now than in 1999, although approximately two-thirds of the doctors were still unwilling to provide this. This result might be due to actual acceptance of hastening death at the end-of-life, better knowledge regarding the use of opioids or both. It is now known that clinically relevant respiratory failure is not a problem when opioids are titrated against cancer pain [35]. Since 1999, there has been growing evidence that the use of opioids for symptom control in advanced diseases has no effect on survival and even high doses of opioids do not seem to shorten life during end-of-life care [20, 21]. In a study conducted in the Netherlands, physicians administered similar dosages of opioids in 1995, 2001 and 2005; however, compared with previous years, in 2005 , they thought that life was shortened by opioids or their intension was to hasten death by administering opioids less frequently [16]. On the other hand, high doses of opioids do cause respiratory depression [17-19], and the potential of opioid to hasten death during end-of-life care is almost impossible to study with prospective randomized trials. Although we did not ask the intention behind physicians' willingness to increase the morphine dose, it was clearly stated in the patient 
scenario that increasing the dose might lead to the patient's death. Oncologists were most reluctant to provide the dose increase, and their opinion did not change between 1999 and 2015. However, they were probably the most familiar with the influences of opioids in clinical practice as well as the studies on this issue. Our results reflect that surgeons, internists and GPs have become increasingly willing to hasten death according to a patient's wishes today than they were 16 years ago, although improved knowledge on the low risk of using opioids during end-of-life care probably influenced our results.

Our results are in line with the study by Miccinesi et al. in which oncologists were the least in favour of using lethal drugs [22]. In our study, the difference between oncologists and other physician groups remained in the results of the logistic regression analysis. These findings might be observed because oncologists take care of these patients on a more regular basis and are perhaps aware that a patient's wish to hasten death does not always imply a genuine wish to die, but might be the result of overwhelming emotional suffering [36], which could be relieved by therapy.

Religion has been confirmed to have a tremendous effect on end-of-life decisions and attitudes towards euthanasia and PAS [1, 22, 27]. In the present study, faith in God was also found to decrease physicians' willingness to administer potentially lethal morphine dose. The number of physicians who had faith in God is lower in the present survey than in 1999, which might be one reason for the increasing support for euthanasia and hastened death. In a previously mentioned study, Löfmark et al. concluded that a non-religious philosophy of life increased physicians' willingness to perform euthanasia and PAS, possibly by emphasizing patient autonomy [27]. Advance directives were relatively uncommon among physicians, but having one seemed to increase the willingness to double the morphine dose; however, the influence of advance directives did not quite reach statistical significance in our logistic regression analysis. To our knowledge, the influence of doctors' own advance directives on end-of-life decisions has not been previously reported.

We suggest that completing an advance directive for oneself may lead to greater acceptance of death, even if this is hastened in a situation without hope for a cure.

Male sex and older age were independently associated with physicians' willingness to double the morphine dose. Previous studies on these factors are somewhat controversial. Females have been shown to be less supportive towards ending life without explicit request from the patient, but also to be more supportive of alleviating pain and other symptoms regardless of the possible life-shortening effects $[22,26]$. In general, younger physicians accept PAS more often but are less willing to withdraw life-prolonging treatments than older physicians $[2,22,26]$. The exact reasons why age and sex are related to the tendency to administer potentially lethal morphine dose in our study remains unknown, but perhaps more experienced physicians do not believe that such a morphine dose would actually kill the patient. Furthermore, men are reported to approve of assisted death more often than women in the general population [1].

Developments in medicine have allowed many interventions for patients with very advanced diseases, but the low survival rates for cardiopulmonary resuscitation (CPR) in the cancer population have not changed [37]. Furthermore, advanced care planning, which increases the prevalence of do-not-resuscitate orders, is probably a more common practice today than in the 1990's [31,38]. In our study, physicians' willingness to start CPR in a patient with very advanced cancer was relatively low and did not change over the study years, in a contrast to the more ethically difficult and complex attitude regarding hastening death. Of interest, the decision about CPR did not influence physicians' willingness to hasten death through the dual effect of a high morphine dose. We suggest that physicians' willingness to hasten death is mainly related to their personal attitudes and values rather than medical facts, which probably guide the decision to withhold CPR.

Finally, we should state that changes in the surrounding society, general attitudes and clinical decision-making in Finland and Europe since the 1990s might have had a substantial influence on our results. In a large international study, the use of lethal doses of drugs after the explicit request of a patient with a terminal illness and uncontrolled symptoms was accepted by $35-78 \%$ of physicians, depending on the country [22]. This large range describes the cultural influence on the difficult decision to hasten death, but the numbers are quite similar to those found in our study. Public attitudes towards assisted death have changed since the 1990s to become more permissible, which has led to legalization of assisted death in some countries and increased political support for it in Finland [1,2]. At the same time, knowledge and awareness of palliative care have grown in Finland through national and international recommendations [39-41]. However, this has happened later than in some other European countries such as the UK $[3,4]$. In addition, patient autonomy and shared decision- making in treatment-choices are increasingly emphasized as important ethical principles throughout Western countries [5, 6, 42]. Patients' rights regarding treatment decisions were incorporated into Finnish law in 1992, and respecting the patient's wishes is currently one of the main principles in the ethical guidelines of the Finnish Medical Association [8, 9]. This social and cultural context together with the shift from paternalism towards a more patient-centred approach in clinical decision-making probably influenced the responding physicians' considerations on the reprehensibility of hastened death and their willingness 
to comply with patients' requests in the ethically complex situation in our study $[6,43]$.

\section{Strengths and limitations of the study}

Limitations of this study need to be acknowledged. Our response rate $(56 \%)$ is a limitation even though our study population is large and the response rate is higher than that in many recent studies [44-46]. The study population is also a representative sample, as it reflects the overall distribution of specialities and gender among Finnish physicians [47]. The follow-up period is long enough to detect relevant changes in attitudes and decision-making. Answers to the hypothetical scenarios might differ from the decisions made in clinical practice, but these questions are difficult to study in real life situations.

\section{Conclusions}

Considering a hypothetical case scenario, Finnish physicians accepted the risk of hastening death more often in 2015 than in 1999. The specialty of the physician, gender, and faith in God strongly influenced their acceptance to this practice. Oncologists were the most reluctant of all the specialists studied to hasten death. Euthanasia, but not assisted suicide, was considered slightly less reprehensible in 2015. Relieving suffering, while considering the justification to hasten death, is a complex ethical question. Therefore, both training in medical ethics and medicine are needed for high quality end-of-life care.

\section{Abbreviations \\ CPR: Cardiopulmonary resuscitation; GP: General practitioner; ICU: Intensive care unit; IQR: Interquartile range; PAS: Physician-assisted suicide; UK: the United Kingdom; VAS: Visual analogue scale}

\section{Funding}

This study was funded by the Seppo Nieminen Legacy Fund, the Signe and Ane Gyllenberg Foundation, the Finnish Medical Association and the Cancer Society of Pirkanmaa. The funders did not have any role in the design of the study; in the collection, analysis or interpretation of the data; or in the writing of the manuscript.

\section{Availability of data and materials}

The datasets used and analysed during the study are available from the corresponding author on reasonable request.

\section{Authors' contributions}

$R P, J L, H H$ and $P L K L$ designed the study outline and the questionnaire. $R P, J$ and PLKL collected the data. RP, JL, PLKL and RM analysed the data. RP and RM performed the final statistical analysis. All the authors contributed to the writing and reviewing of the manuscript and approved the final manuscript.

\section{Ethics approval and consent to participate}

The study was approved by the Regional Ethics Committee of Tampere University Hospital, Finland (R15101) and participation was voluntary and anonymous.

\section{Competing interests}

The authors declare that they have no competing interests.

\section{Publisher's Note}

Springer Nature remains neutral with regard to jurisdictional claims in published maps and institutional affiliations.

\section{Author details}

Faculty of Medicine and Life Sciences, University of Tampere, Tampere, Finland. ${ }^{2}$ Department of Oncology, Palliative Care Unit, Tampere University Hospital, Teiskontie 35, R-building, 33520 Tampere, Finland. ${ }^{3}$ Faculty of Social Sciences, University of Tampere, Tampere, Finland. ${ }^{4}$ Rehabilitation Center Apila, Kangasala, Finland.

Received: 7 November 2017 Accepted: 16 May 2018

Published online: 30 May 2018

\section{References}

1. Emanuel EJ, Onwuteaka-Philipsen BD, Urwin JW, Cohen J. Attitudes and practices of euthanasia and physician-assisted suicide in the United States, Canada, and Europe. JAMA. 2016;316(1):79.

2. Louhiala P, Enkovaara H, Halila H, Palve H, Vanska J. Finnish physicians' attitudes towards active euthanasia have become more positive over the last 10 years. J Med Ethics. 2015;41(4):353-5.

3. Centeno C, Lynch T, Donea O. EAPC atlas of PC in Europe 2013-full edition. Milano. EAPC. 2013. http://hdl.handle.net/10171/29291. Accessed 18 Jan 2018.

4. Centeno C, Clark D, Lynch T, Racafort J, Praill D, De Lima L, Greenwood A, Flores LA, Brasch S, Giordano A, EAPC Task Force. Facts and indicators on palliative care development in 52 countries of the WHO European region: results of an EAPC task force. Palliat Med. 2007;21(6):463-71.

5. Austin CA, Mohottige D, Sudore RL, Smith AK, Hanson LC. Tools to promote shared decision making in serious illness: a systematic review. JAMA Intern Med. 2015:175(7):1213-21.

6. Kon AA. The shared decision-making continuum. JAMA. 2010;304(8):903-4.

7. Graber MA, Tansey JF. Autonomy, consent, and limiting healthcare costs. J Med Ethics. 2005;31(7):424-6.

8. Finlex Data Bank. Laki potilaan asemasta ja oikeuksista. Potilaan itsemääräämisoikeus. 12.8.1992/785, 6\$. 1992. https://www.finlex.fi/fi/laki/ajantasa/ 1992/19920785. Accessed 21 Jan 2018.

9. The Finnish Medical Association: Lääkärin Etiikka (Physician's Ethic). 2013. https://www.laakariliitto.fi/site/assets/files/1273/laakarin_etiikka_2013.pdf. Accessed 22 Jan 2018

10. World Health Organization. WHO Definition of Palliative Care. Geneva; 2002. http://www.who.int/cancer/palliative/definition/en/. Accessed 23 May 2017

11. De Lima L, Woodruff R, Pettus K, Downing J, Buitrago R, Munyoro E, Venkateswaran C, Bhatnagar S, Radbruch L. International Association for Hospice and Palliative Care Position Statement: euthanasia and physicianassisted suicide. J Palliat Med. 2017;20(1):8-14.

12. Radbruch L, Leget C, Bahr P, Muller-Busch C, Ellershaw J, de Conno F, Vanden Berghe P, Board members of EAPC. Euthanasia and physicianassisted suicide: a white paper from the European Association for Palliative Care. Palliat Med. 2016;30(2):104-16

13. Lindblad A, Juth N, Furst CJ, Lynoe N. When enough is enough; terminating life-sustaining treatment at the patient's request: a survey of attitudes among Swedish physicians and the general public. J Med Ethics. 2010:36(5):284-9.

14. Billings JA. Double effect: a useful rule that alone cannot justify hastening death. J Med Ethics. 2011;37(7):437-40.

15. Cavanaugh TA. The ethics of death-hastening or death-causing palliative analgesic administration to the terminally ill. J Pain Symptom Manag. 1996;12(4):248-54.

16. Rurup ML, Borgsteede SD, van der Heide A, van der Maas PJ, OnwuteakaPhilipsen BD. Trends in the use of opioids at the end of life and the expected effects on hastening death. J Pain Symptom Manag. 2009;37(2):144-55.

17. Boom M, Niesters M, Sarton E, Aarts L, Smith TW, Dahan A. Non-analgesic effects of opioids: opioid-induced respiratory depression. Curr Pharm Des. 2012:18(37):5994-6004

18. Dahan A, Overdyk F, Smith T, Aarts L, Niesters M. Pharmacovigilance: a review of opioid- induced respiratory depression in chronic pain patients. Pain Physician. 2013;16(2):E85-94

19. Pattinson KT. Opioids and The control of respiration. Br J Anaesth. 2008; 100(6):747-58.

20. Lopez-Saca JM, Guzman JL, Centeno C. A systematic review of the influence of opioids on advanced cancer patient survival. Curr Opin Support Palliat Care. 2013;7(4):424-30

21. Sykes N, Thorns A. The use of opioids and sedatives at the end of life. Lancet Oncol. 2003;4(5):312-8.

22. Miccinesi G, Fischer S, Paci E, Onwuteaka-Philipsen BD, Cartwright C, van der Heide A, Nilstun T, Norup M, Mortier F, EURELD consortium. Physicians' 
attitudes towards end-of-life decisions: a comparison between seven countries. Soc Sci Med. 2005;60(9):1961-74.

23. Seale $C$. Hastening death in end-of-life care: a survey of doctors. Soc Sci Med. 2009;69(11):1659-66.

24. Hinkka H, Kosunen E, Metsanoja R, Lammi UK, Kellokumpu-Lehtinen P. To resuscitate or not: a dilemma in terminal cancer care. Resuscitation. 2001;49(3):289-97.

25. Hinkka H, Kosunen E, Lammi EK, Metsanoja R, Puustelli A, KellokumpuLehtinen $P$. Decision making in terminal care: a survey of finnish doctors' treatment decisions in end-of-life scenarios involving a terminal cancer and a terminal dementia patient. Palliat Med. 2002;16(3):195-204

26. Hinkka H, Kosunen E, Metsanoja R, Lammi UK, Kellokumpu-Lehtinen P. Factors affecting physicians' decisions to forgo life-sustaining treatments in terminal care. J Med Ethics. 2002;28(2):109-14.

27. Löfmark R, Nilstun T, Cartwright C, Fischer S, van der Heide A, Mortier F, Norup M, Simonato L, Onwuteaka-Philipsen BD, EURELD Consortium. Physicians' experiences with end-of-life decision- making: survey in 6 European countries and Australia. BMC Med. 2008;6:4. 7015-6-4

28. Temel JS, Greer JA, Muzikansky A, Gallagher ER, Admane S, Jackson VA, Dahlin CM, Blinderman CD, Jacobsen J, Pirl WF, Billings JA, Lynch TJ. Early palliative care for patients with metastatic non- small-cell lung cancer. $\mathrm{N}$ Engl J Med. 2010;363(8):733-42.

29. Zimmermann C, Swami N, Krzyzanowska M, Hannon B, Leighl N, Oza A, Moore M, Rydall A, Rodin G, Tannock I, Donner A, Lo C. Early palliative care for patients with advanced cancer: a cluster-randomised controlled trial. Lancet. 2014:383(9930):1721-30.

30. Houben CH, Spruit MA, Groenen MT, Wouters EF, Janssen DJ. Efficacy of advance care planning: a systematic review and meta-analysis. J Am Med Dir Assoc. 2014;15(7):477-89.

31. Brinkman-Stoppelenburg A, Rietjens JA, van der Heide A. The effects of advance care planning on end-of-life care: a systematic review. Palliat Med. 2014;28(8):1000-25.

32. Johnston SC. Advance directives: from the perspective of the patient and the physician. J R Soc Med. 1996;89(10):568-70.

33. Oulton J, Rhodes SM, Howe C, Fain MJ, Mohler MJ. Advance directives for older adults in the emergency department: a systematic review. J Palliat Med. 2015;18(6):500-5.

34. Laakkonen ML, Pitkala KH, Strandberg TE, Berglind S, Tilvis RS. Living will, resuscitation preferences, and attitudes towards life in an aged population. Gerontology. 2004;50(4):247-54.

35. Estfan B, Mahmoud F, Shaheen P, Davis MP, Lasheen W, Rivera N, Legrand SB, Lagman RL, Walsh D, Rybicki L. Respiratory function during parenteral opioid titration for cancer pain. Palliat Med. 2007;21(2):81-6.

36. Monforte-Royo C, Villavicencio-Chavez C, Tomas-Sabado J, Mahtani-Chugani V, Balaguer A. What lies behind the wish to hasten death? A systematic review and meta-ethnography from the perspective of patients. PLoS One. 2012;7(5):e37117.

37. Miller AH, Sandoval M, Wattana M, Page VD, Todd KH. Cardiopulmonary resuscitation outcomes in a cancer center emergency department. Springerplus. 2015;4:106. 015-0884-z. eCollection 2015

38. Tan A, Seah A, Chua G, Lim TK, Phua J. Impact of a palliative care initiative on end-of-life care in the general wards: a before-and-after study. Palliat Med. 2014;28(1):34-41.

39. Ministry of Social Affairs and Health. Providing palliative treatment and end-oflife care. 2017. http://urn.fi/URN:ISBN:978-952-00-3896-0. Accessed 29 Jan 2018.

40. The Finnish Medical Society Duodecim. Current Care Guidelines. Palliative (symptomatic) care of (imminently) dying patients. 2012. http://www. kaypahoito.fi/web/kh/suositukset/suositus?id=hoi50063. Accessed 17 Jan 2018.

41. European Association for Palliative Care. EAPC Recommendations. 2017. http:// www.eapcnet.eu/Themes/Resources/ClinicalCare/PublicationsDocuments/ EAPCRecommendations.aspx. Accessed 17 Jan 2018.

42. Stiggelbout AM, Pieterse AH, De Haes JC. Shared decision making: concepts, evidence, and practice. Patient Educ Couns. 2015;98(10):1172-9.

43. National Institute for Health and Care Excellence. Clinical Guidelines. Care of Dying Adults in the Last Days of Life. 2015. National Clinical Guideline Centre, London. https://www.nice.org.uk/guidance/ng31/ resources/care-of-dying-adults-in-the-last-days-of-life-\%20pdf1837387324357. Accessed 18 Jan 2018
44. Cartwright CM, White BP, Willmott L, Williams G, Parker MH. Palliative care and other physicians' knowledge, attitudes and practice relating to the law on withholding/withdrawing life- sustaining treatment: survey results. Palliat Med. 2016;30(2):171-9.

45. Escher M, Perneger TV, Rudaz S, Dayer P, Perrier A. Impact of advance directives and a health care proxy on doctors' decisions: a randomized trial. J Pain Symptom Manag. 2014;47(1):1-11.

46. Nakazawa K, Kizawa Y, Maeno T, Takayashiki A, Abe Y, Hamano J, Maeno T. Palliative care physicians' practices and attitudes regarding advance care planning in palliative care units in Japan: a nationwide survey. Am J Hosp Palliat Care. 2014;31(7):699-709.

47. The Finnish Medical Association: Physicians in Finland, statistics on physicians and the health care system 2016. [https://www.laakariliitto. fi/site/assets/files/1268/I16_tilasto2016_net1_170114.pdf]. Accessed 27 December 2017.

\section{Ready to submit your research? Choose BMC and benefit from:}

- fast, convenient online submission

- thorough peer review by experienced researchers in your field

- rapid publication on acceptance

- support for research data, including large and complex data types

- gold Open Access which fosters wider collaboration and increased citations

- maximum visibility for your research: over $100 \mathrm{M}$ website views per year

At BMC, research is always in progress.

Learn more biomedcentral.com/submissions 